\title{
The Status Quo, Issues and Foreign Experiences of Deep Sea Aquaculture Equipment of China
}

\author{
Zhenzhen Zhang, Yiyang Liu* \\ Research Centre of Marine Economy, Shanghai Ocean University, Shanghai, 201306, China \\ * Corresponding Author: Yiyang Liu
}

Keywords: deep sea aquaculture equipment; deep sea cage farming; issues; international experiences

\begin{abstract}
The demand for marine products in China is expected to be a continuous rising trend in the next 20 years. In the context of the declining fishery resources and limited development of offshore marine product development, deep-sea cage farming has become an inevitable option for China's marine fishery development. Starting from multiple aspects including equipment development, supporting technologies, brand structure and industrialization, the status quo of deep-sea cage farming of China is analyzed in this paper, and issues existed in development are also elaborated. This paper believes that to promote the development of deep-sea cage farming of China, cage farming and supporting technologies shall be improved, the industry chain shall be perfected, the industrialization shall be lifted, and government services and management shall be given to play.
\end{abstract}

\section{Research Background}

The marine aquaculture in China has made substantial achievements ever since the "raising first" guideline has been determined for the fishery industry. In 2016, the total output of China's marine aquaculture is 19.6313 million tons, the total output value is 314.039 billion RMB, and the total export volume of marine products is 8.2791 million tons, indicating the important role of China in the world's marine aquaculture industry [1]. However, the marine aquaculture in China is mainly concentrated in bays, mud flats and offshore waters and the use ratio of deep sea aquaculture space is extremely low (Wang Dongshi et al., 2015). Therefore, it is one of China's marine aquaculture industry development strategies to vigorously develop deep sea cage aquaculture and industrialized marine aquaculture (Chen Yusheng, 2012). In the context of the new era where the important strategy "blue granary" is proposed, deep sea cage aquaculture becomes one of the critical options for the expansion of marine aquaculture space, which is even more prominently significant to promote it and develop it [2].

Deep sea cage aquaculture refers to a kind of offshore marine aquaculture in deep sea, which normally uses a cage that consists net rack, netting, floating device and anchor device, with supporting measures such as bait-casting system, underwater monitoring system, and disease prevention system. As an advanced marine aquaculture method, deep sea cage aquaculture indicates that the industry of China is becoming intensifying. Large-scale deep sea appeared in late 20th century in China when a number of large stormproof deep-water cages were imported from Norway to Hainan (HDPE model).

Deep sea cage aquaculture is of a series of advantages. It expands the farming space, protects and improves the marine environment, increases production efficiency and product quality, encourages fishermen to join the industry, and increases their income etc. Currently, there are numerous shortcomings in China's deep-sea cage aquaculture such as technologies, personnel training, relevant policy support and management policies, all of which have been impeding the forming and development of the deep-sea cage aquaculture industry chain.

Existing literatures mainly focus on technological analysis in terms of deep sea cage aquaculture, and the research literature regarding the personnel training and management mechanism of deep sea cage aquaculture are still lacking. Based on that, the status quo and existing issues of China's 
deep-sea cage aquaculture are analyzed in this paper in combination of the development experiences and inspirations of deep sea cage aquaculture in foreign countries, offering policy references for the future development of China's deep-sea cage aquaculture

\section{Status Quo and Issues of Deep Sea Aquaculture Equipment Development of China}

Deep sea cage aquaculture is an imported technology. China has achieved substantial progress yet certain issues still exist, which are mainly manifested in the following aspects.

\subsection{The technological innovation of farming cage shall be strengthened immediately}

Cage is the support and carrier of deep sea box-based aquaculture system, and a decisive factor that determines farming efficiency. What's more, it is the key controlling point about whether the farming is successful. Most cages used in early days were imported from foreign countries. As we became more experienced and learned advanced experiences of other countries, however, the production of the main body of cages has realized localization. But the cages manufactured in China are still lagging traditional aquaculture powers in terms of materials, design concepts and precision. Essentially speaking, such gap is led by two reasons. First, compared with those countries which are known for cage manufacturing, China's development history is shorter, and we are still probing some core technologies and ideas. In addition, China is a country of vast waters where northern and southern water bodies are greatly varied, and the underwater conditions are complicated and variant. Also, different cages shall be used in different provinces, making the research even more difficult. Second, the R\&D of technological products in today's market-oriented economy is under the influence of market demands, and the cost of technological innovation is not entirely directly proportional to user experiences and returns. The users of deep sea aquaculture cages pursue profits, while high costs of purchase and use are also an adverse factor that prevents the industry from becoming large scale. Therefore, it is an important direction for China's cage research in the future to develop practical and technologically innovative cages that suit the situations of China on the basis of cost control [3].

\subsection{The cage research and development shall be attached with importance and existing supporting technologies are relatively backward}

The research and development of deep sea cage in China have been making new achievements continuously since the "deep sea stormproof cage development" project has already been listed as one of the national hi-tech R\&D plan (the "863" plan) in early days. Some of the technologies have reached international advanced level. For example, in 2012, the development and application project of deep sea stormproof cage, a project undertaken by South China Sea Fisheries Institute of CAFS, has reached international advanced level, which has bridged several technological gaps in China. But the project result is difficult to be promoted due to high cost. Deep sea cage aquaculture is a comprehensive system consisted of cage and supporting facilities, so the perfection and improvement of such supporting facilities may directly improve aquaculture production efficiency. Currently, the deep-sea aquaculture equipment of China is merely being experimented and tested in certain deep-sea cage aquaculture bases (Chen Fuxiao et al., 2015), and they are not commonly promoted in the country's deep-sea cage aquaculture industry.

\subsection{The species are not diverse, and without famous brand}

The species of marine fishes in China are multitudinous, yet few of them suit deep sea cage aquaculture. The traits of certain species even decline due to limited breeding and farming conditions. The species that are suitable to deep sea cage aquaculture often come with following features, which are of larger size, quicker growth, better meat quality, broader sources of baits, and large market demand. Main breeds today haven't gone through selection, purification and rejuvenation, so some of them are of poorer meat quality. In addition, as a result of the backward fry rearing application in China, there isn’t any famous brand, hence no competitiveness in international market. China enjoys 
vast sea territory of which the environment is complicated. The method of breeding different species in different marine environments hasn’t been given to play.

\subsection{The industrialization level of deep-sea cage farming is yet to be improved}

Issues such as short industry chain, small scale of operation, and low industrialization level exist in China's deep-sea cage aquaculture today. Specifically speaking, those issues can be analyzed from two aspects. As for the horizontal direction of the industry chain, even though the deep sea cage aquaculture in China has witnessed rapid development in recent years during which the industry outline has been preliminarily defined and periodical achievements have been made, the general distribution of deep sea cage aquaculture in China is still featured as "small scale and scattered", and low organizational degree; the cooperation in every link before, amidst and after production as well as management level are still yet to be substantially improved, and the communication and mutual assistance among different regions are still yet to be deepened. Fish farmers are still not active enough to join marine aquaculture industry association, fishery mutual insurance association, and aquaculture cooperative; the scale economy and knowledge-based economy of deep sea cage aquaculture are still yet to be taken in shape. As for the vertical direction of the industry chain, the length of the industry chain of deep sea cage aquaculture is still yet to be lengthened. For example, deficiencies are still found in certain high-value added industry sectors including deep processing, packaging, branding, foreign exchange earning via trading of aquaculture products, and the expandability of the front-end and rear-end of the industry is still weak [4].

\section{Brief Introduction of Deep-Sea Cage Aquaculture in Norway}

The large-scale deep-sea cage aquaculture in Norway is the world's most advanced and typical industry. Starting from scratch, it didn't take too long for Norway to be the global leader since its development speed has been dramatic.

Deep-sea cages became larger. The R\&D of deep-sea cage in Norway has been leading in the world's cage industry. The deep-sea cage perimeter used to be $40 \mathrm{~m}$ during its early development phase in 1970s and today the number is $80 \mathrm{~m}$ and $120 \mathrm{~m}$. The largest cage ever made so far has a perimeter as long as $180 \mathrm{~m}$ with a depth of $40 \mathrm{~m}$. Currently, the HDPE deep-sea cage of which the perimeter is from 60 to $120 \mathrm{~m}$ is the most common type used in Norway. It is capable of resisting 12 Beaufort Scale wind, $5 \mathrm{~m}$ high waves and currents that are below $1 \mathrm{~m} / \mathrm{s}$. The highest output per cage is above 200t, and the average life span is above 10 years. The R\&D of large fish farm service vessels of Norway is of great significance for ocean deep-sea cage aquaculture. The large deep-sea fish farm service vessel designed by NSK Ship Design in 2015, a Norwegian ship maker, is 430m long and $54 \mathrm{~m}$ wide. One vessel is able to accommodate 10,000 tons of marketable salmons or more than 2 million juvenile fish. Besides, the vessel can sink $10 \mathrm{~m}$ below the sea level. The vessel is of steel structure with $650 \mathrm{~m} * 50 \mathrm{~m}$ farming cages of which the depth is as deep as $60 \mathrm{~m}$. It is easy to see that Norwegian deep-sea cage business is increasingly becoming larger and super large scale, and the environment and products are getting closer to being purely natural, guaranteeing environmental-friendliness and product quality too.

Perfect supporting equipment. The supporting equipment of deep-sea cage aquaculture in Norway has always been perfect, which is attributed to the government's focus and support. The output value of fishery in Norway is 5.4 billion USD in 2015. Each year, Norway spends roughly 400 million USD on marine research so that supporting equipment can be upgraded. Normally, large deep-sea cages in Norway are equipped with a smart management system which incorporates automated bait casting system, automated fish fry counting device, underwater monitoring system, automated graded fish collection and automated dead fish collection device. As those supporting equipment are commonly applied in Norway's deep-sea cage aquaculture, manpower is gradually being released from fishery activities, and all works related to farming management and $\mathrm{R} \& \mathrm{D}$ are becoming automated and smart.

Reasonable personnel training mechanism and strict management system. The personnel training 
mechanism and strict management system, which were gradually established during the development process of Norway's deep-sea cage aquaculture, improved the product quality of the country's deep-sea cage aquaculture and promoted the industry development to a great extent. From its aquaculture permission system which was established earlier to today's perfect law system, the experiences of Norway provide the world's deep-sea cage aquaculture with advanced and strict standards. For example, practitioners have to receive training for more than three years and practical experiences in the industry for more than two years, which is a request that all practitioners must have qualified professional knowledge and literacy. Daily management such as the breeding intensity, annual bait casting volume, distance between every two fishery farms, and how to deal with fish died of diseases are all strictly regulated, and the code of conduct of deep-sea cage aquaculture provides specific and quantifiable standards, offering a legal basis for the industry. In addition, the application for a permit must meet the standards of environment protection so that no pollution or disease will be generated, which reflects the fact that the deep-sea cage aquaculture in Norway attaches great importance to a healthy and sustainable development.

\section{Countermeasures for Deep Sea Cage Aquaculture in China}

\subsection{The cage farming and supporting technologies shall be specifically improved}

China has been constantly making new progresses in deep sea cage aquaculture. Nevertheless, the supporting technologies of China are still yet to be improved in comparison with other countries such as Norway. For example, the development and application such as water quality monitoring, automated bait casting, real-time monitoring, automated fishing and grading equipment, all of which may substantially improve the efficiency and effectiveness of deep sea cage aquaculture. The government shall pay more attention on technological R\&D, reasonably invest more capital, and focus on the training of technical personnel. Besides, China has vast territorial waters so deep-sea cage and supporting equipment of different specifications and performances shall be developed in allusion to the conditions of different waters.

\subsection{The industry chain shall be perfected and the industrialization level shall be lifted}

First, the professional training provided for the practitioners of deep sea cage aquaculture shall be strengthened to improve the general qualities of all people, so that the breeding efficiency and quality can be improved too. The construction of an information service platform is important because it helps breeders to obtain market demands for them to reasonably arrange works. Second, large-scale aquaculture enterprises and social service organizations shall be fostered. Funds and policies can be granted by the government to give aid to large-scale aquaculture enterprises and cooperatives and improve the technological and management level of deep sea cage aquaculture. Fishermen shall be actively guided to participate in deep sea cage aquaculture to expand the scale and garner scale merits. Third, more aids shall be given to enterprises for them to develop. The government may enhance the construction of infrastructure in areas which are suitable for deep sea cage aquaculture, support the development of cold-chain logistics, develop order-based fishery, minimize trading time, and reduce product loss; support marine product deep processing enterprises, increase the added values of fish products, meet different needs of different consumption levels, and improve the industrialization level of deep sea cage aquaculture.

\subsection{The government services and management shall be given to play}

More aids shall be given by the government, and those deep sea cage aquaculture enterprises or fishermen households which have reached certain scale can be financially subsidized; local banks shall be encouraged to provide favorable loan policies for aquaculture in order to solve financial issues of deep sea cage aquaculture; professional cooperatives shall be encouraged and social service system shall be perfected so that more comprehensive services can be provided to fishermen households and they can be encouraged to participate in deep sea aquaculture. Meanwhile, the 
government shall play the role as a supervisor and manager. The selection, planning and layout for deep sea cage aquaculture, the code of conduct for daily aquaculture activities, the quality requirement for practitioners, the product quality standard, all of which are governed by the government. The permission system in Norway provides a helpful reference. Also, a perfect legal basis shall be created and the code of conduct shall be specified. On the one hand, they provide references for daily works, on the other hand, they provide a legal basis for the punishment against any violations, bringing convenience for the government to manage the industry.

\section{Acknowledgement}

This research was financially supported by the Opening Foundation of Institute of Marine Science of Shanghai Ocean University (Grant No. A1-0203-00-300112).

\section{References}

[1] Yan Guoqi, Ni Xiaohui, Mo Jiasi. Research status and development tendency of deep sea aquaculture equipments: a review [J]. Journal of Dalian Ocean University, 2018, 33(1): 123-129.

[2] Xu Hao, Chen Zhixin, Cai Jiqiang, et al. Research on the development of deep sea aquaculture engineering equipment in China [J]. Fishery Modernization, 2016, 43(3): 1-6.

[3] Cai Jiqiang, Zhang Yulei, Li Jianyu, et al. General Technology Research of 100 Thousand Ton Deep Sea Aquaculture Platform [J]. Ship Engineering, 2017, 39(1): 198-203.

[4] Chen Yusheng, Fang Ruijing, Qiao Juan. The Advantages, Problems and Strategic Choice of the Mariculture Industry in China [J]. Issues in Agricultural Economy, 2012(6): 72-77+112. 